\title{
Value Orientation of Students of the Russian Far East
}

\author{
Lutsenko Ekaterina \\ Department of Economics, Management and \\ Financial Law \\ Sholom-Aleichem Priamursky State \\ University \\ Birobidzhan,Russia \\ luce-ekaterina@yandex.ru
}

\author{
Bazhenova Natalya \\ Department of Economics, Management and \\ Financial Law \\ Sholom-Aleichem Priamursky State \\ University \\ Birobidzhan,Russia \\ n-bazhenova@yandex.ru
}

\author{
Bogachenko Natalia \\ the Faculty of Philology and Journalism \\ Sholom-Aleichem Priamursky State \\ University \\ Birobidzhan,Russia \\ nataliya-bogachenko@yandex.ru
}

\begin{abstract}
New norms, values, rules of social behaviour appear because of social and economic reforms and the process of establishing market relations in our country. Such traditional values of Russian culture as collectivism, priority of spiritual over material, self-sacrifice, conciliarity and absence of covetousness do not contribute to the development and prosperity of Russia in modern conditions (E. Yasin). Nowadays, there is a tendency to follow Western ideals and values that encourage individualism, freedom and human rights, entrepreneurship and well-being. As a result, we can witness a shift in emphasis in the Russian consciousness from the interests of the state to the interests of an individual, reassessment of previously existing values and ambiguous perception of new ones, search for strong life orientations.

Studentship is a period of intensive development of the system of value orientation, which influences character and personality formation. Young people strive to identify the most important goals, ideals, according to which they carry out their life activities and choose various means to develop their plans.

The article presents a sociological analysis of value orientation of students of the Russian Far East illustrated through the example of the Jewish Autonomous region.
\end{abstract}

Keywords - value, youth, orientation, Far East, students

\section{INTRODUCTION}

The reassessment and crisis of values is manifested most of all in minds of adolescents and young adults. Meanwhile, modern authors of psychological and pedagogical works often continue to use data received many years ago, without taking into account the fact that value orientation of modern youth considerably differs from ideals of their peers of the 1940-60s and 1980-90s.

Studentship is a period of intensive development of the system of value orientation, which influences the character and personality formation. Young people strive to identify the most important goals, ideals, according to which they carry out their life activities and choose various means to implement their plans. Today, however, young men and women have to choose a system of values as well as understand them.

Studentship is a full-fledged, independent, sociocultural community, that is active in the sphere of education and 'functioning in the system of higher education', 'acts as an object of production, the subject of which is not a thing, but a person' [8]. Therefore, the main function of this production is educational activity.

Structural definition of studentship is based on one of the most important criteria by which a group of young people can be attributed to the studentship. This criterion is connected with the intermediate position of students between a passive object of social care and an active subject of a social action. Students, on the one hand, are a subject of the state educational guardianship and educational and cultural care of the society, and, on the other hand, are able to take the most active part in public policy, including economic production and political activity.

The problem under consideration is very important because we can observe the opposition between social conditions that make special requirements to forming the system of value orientations of a personality, and insufficient studying of psychological factors and mechanisms of its development.

This article is devoted to the examination of peculiarities of student's value orientation in the period of their university study.

The aim of the work is to study peculiarities of student's value orientation at Sholom-Aleichem Priamursky State University.

The object of the research is value orientation.

The subject of the research is peculiarities of students' value orientation.

The methodological framework of the study is provided with the works of Russian psychologists E.N. Belova, G.E. Zalessky, A.G. Zdravomyslov, V.B. Olshansky, E.L. Rudneva, T.N. Semenkova, L.L. Shpak, V.A. Yadova on the problem of value orientation.

\section{RESULTS AND DISCUSSION}

Values are integrated into life to a greater or lesser extent so that the trajectory of an individual's life demonstrates them through behaviour and reveals their renewal. Values can be fixed, (felt, reflected) in consciousness and verbalized, i.e. articulated, functioning as an explanation of what a person is or how he would like to appear in other people's perception. Among the choosing forms there appeared the contours of the path taken by a subject and an ordered, unified, integrated and coordinated set of values, which largely crystallizes the certainty of an individual subject. 
Value is a system of patterns generally accepted in a social organization. These patterns help people correlate and mediate their interactions with each other. Values are a matrix of human socialization [1]. They help to systematize and generalize social life experience. Any object can be a social value, if it serves as a focus of aspirations, desires of groups or individuals, is considered as an important condition of existence. Values are implemented by means of a variety of social norms [2]. Evaluation is one of the socio-psychological forms of social norms. Social values shared by individuals and groups function as a measure of assessing actions in terms of their relationship with the system of values. The most important element of an individual's behaviour, namely assessing / structuring a situation is greatly dependent on his system of values.

The analysis of the situation is the most important part of a person's behavior; it is largely depends on his system of values. Values can be considered both as elements of the cognitive structure of a person, and as elements of his motivational sphere, i.e. values perform two functions, because of the dual nature of the value system, determined simultaneously by individual and social experience. This 'duality' of values can also be explained by their 'sense bearing' character. According to V. Frankl, G. Allport values play the role of the meaning of human life. V. Frankl assets that the meaning cannot be 'invented' by a human being - it must be 'found'. But the meaning cannot be given 'from the outside'. Thus, on the one hand, it is life that determines the goals which can be conceived by a person, and on the other hand the understanding of a specific situation is a conscious choice of a person. Therefore, meanings are born at the intersection of 'inner and outer'. These meanings are considered to be values. Thus, values can be defined as universals of meaning, crystallizing in situations typical to the society or even the humanity.

The values of the personality are organized into specific systems (hierarchies). The complex hierarchical structure of the value system is determined by various social conditions of the development and activity of the individual. Criteria of ranking value orientations by a person are ambiguous; such factors as the significance of value orientations to the society or their importance for the individual himself may influence his preference.

There are various theories and approaches to studying the hierarchical structure of personal values. For example, A.I. Dontsov offers the system of values represented in various forms:

1) system of the most stable and combined 'core' value standards of a personality;

2) system of personal standards in regards to the environment and himself in some areas of his social activities, i.e. the value orientation of an individual;

3) set of standards that are strictly implemented in similar conditions.

V.A. Yadov developed the theory of a hierarchical system of dispositions.
Its lowest level contains stated objectives, which are set on the basis of vital needs in the simplest situations.

The second level includes the system of social objectives.

The third level contains the basic social objectives related to the general orientation of personality's interests in a certain sphere of social activity.

The highest level is a system of value orientations to the goals of life activity and means of achieving these goals, determined by the general conditions of the individual's life.

The theory of M. Rokeach reveals the comparative importance of values for an individual, i.e. the preference of each value for an individual. According to M. Rokeach, human values have such main features as:

- origins of human values can be traced in culture, society, its institutions and personality;

- the influence of values can be seen in almost all social phenomena that deserve to be studied;

- the total number of inherited human values is relatively small;

- all people have the same values, although to different degrees;

- values are arranged into systems [2].

Moreover, M. Rokeach divides values taking into consideration the traditional opposition of values-goals and values-means. Accordingly, he identifies two classes of values:

- terminal values, namely beliefs that some ultimate goal of the individual existence from a personal or social point of view is worth striving for it;

- instrumental values, namely beliefs that a particular course of action is personally and socially preferable in any situation.

Terminal values are more stable than instrumental values, they have less interindividual variability. With the help of M. Rokeach's technique, developed on the basis of his theory, a huge number of various studies were conducted, which prove that human actions are determined by the priority of his values. For example, people who attach most importance to 'salvation', regularly go to church; people who appreciate 'health', lead, as a rule, a healthy lifestyle [5]. A large number of studies were devoted to the study of value priorities in relation to the political orientation of respondents, as well as to the study of national values priorities.

Social relations in which a person is included in the course of his life determine the content of value orientations. The formation of value orientations as internal determinants of activity is connected with the formation of a system of values. Combined value concepts are located at the core of value orientations; they reflect the social and individual experience of a person, his diverse relationships with the most important aspects of reality.

In our paper, we will take the definition given by S.L. Rubinstein that value is an importance of something for a person in the world, and only the recognized value is able to perform the most important value function, the function of a behaviour orientation. The value orientation manifests itself in 
a certain orientation of consciousness and behaviour revealed in socially significant deals and actions [8].

The analysis of the data given in the work is based on the results of the research conducted during 2017 and devoted to the study of student's value orientation at Sholom-Aleichem Priamursky State University.

The type of the research is analytical, because we aimed at describing the structural elements of the studied processes, and finding out the reasons that compile them and determine the nature of this phenomenon.

The respondents are students, citizens of the Russian Federation, living and receiving higher education in the Far Eastern region (the Jewish Autonomous region). The subtype of the research corresponds to a spot analysis, since the information about the object was collected at the time of studying it. The form of the survey is an on-site and off-site questioning. The type of the survey is a wide-scale one. The sample set of the research included 200 people.

'The path to studentship' begins much earlier than a student life. Psychologists constantly document an existence of a strong desire to become a student in life plans of young people finishing secondary school. Of course, life will amend these plans. However, it proves that the dominant orientation is that of mental work and a desire to get higher education. For young people, going into further academic study is a great social, moral and psychological value.

Many participants of the survey are not satisfied with their own laziness, short temper, excessive kindness and trustfulness, rudeness, jealousy, arrogance, lack of restraint, lack of confidence in their own abilities. But there are also people who are satisfied with themselves $(7 \%) .48 \%$ of people believe that a person should forgive everything. Also $48 \%$ believe that, on the contrary, it is impossible to forgive everything. It is impossible to forgive such things as betrayal, treason, lies, hypocrisy, and disrespect. $4 \%$ of people abstained from answering.

To the question 'what would you like to change in your life and in the life of the society?' $45 \%$ of people answered that they were satisfied with everything in their lives and did not want to change anything. Among the other answers there were such as to go to another school; have a two-parent family, find love; be less serious, be easy-going; exclude from their lives people who are unpleasant.

They want to reduce the number of unemployed, orphans, drug addicts, and alcoholics, single and poor people in the society. They dream of an effective fight against terrorism, the absence of war, confidence in the future, want to change universal values, attitude to people, including to the working class. $7 \%$ of people think that nothing can be changed.

To the question "what was the main reason that made you go to the university, several options were offered. $45 \%$ of the respondents preferred the ability to increase their intellectual level; such a value as 'getting a profession' was chosen by $20 \%$ of people as well as the value of 'selfaffirmation' (20\%); the value of 'the necessity to obtain a diploma' was preferred by $10 \%$ and $5 \%$ of the respondents chose the value of 'the opportunity to improve their financial situation.'

Fifty five percent of the students wish to apply the acquired knowledge in practice. $30 \%$ of the respondents have not chosen their future professions yet and 15\% will not pursue their professions.

In the course of the analysis of the results according to M. Rokeach's 'Value orientations' method it was found out that the value of 'Health' (physical and mental) from the list of terminal values ranked by the students is prior for $42.1 \%$. The second ranking place is given to the value of a happy family life, it was important for $21 \%$ of the students.

The value of 'development' (self-improvement, constant physical and spiritual perfection) was the second in the hierarchy of values.

Striving for self-development is one of the main goals in mastering the profession of a teacher and its value is very important throughout the life of a teacher.

The value of a 'happy family life' was the third in the hierarchy of values. The need of most respondents for a happy family life is explained by the fact that the majority of students are women, guardians of the family hearth, many of them have their own families and children, and many of them are just going to make a family and, accordingly, it is the most important value for them in life.

Such values as active life, life wisdom (maturity of judgments and common sense sharpened by life experience); the presence of good and faithful friends; knowledge (the possibility of extending their education, widening their horizons, developing their culture; intellectual development); freedom (independence in judgments and actions); selfconfidence (inner harmony, freedom from internal contradictions, doubts) are the fourth in the rank.

Thus, there is good reason that such values as the need for honesty, truthfulness, sincerity; tolerance (to views and opinions of others, an ability to forgive other people's mistakes and errors), as well as accuracy, good breeding (good manners), diligence (discipline), open-mindedness occupy an important place in forming future teachers, as the actualization of these needs constitutes the main basis of the profession of the teacher.

Civic position is one of the indicators of value orientation of the modern society. It is formed under the influence of a number of factors (national, cultural, etc.) by different agents (government institution, education, family) [7]. The words 'Russia', 'Russian Federation' arouse positive feelings, emotions such as 'homeland', 'house', and 'pride' on the majority of young people $(43.5 \%)$. For $22.5 \%$ of the respondents, these words are associated with the authorities, namely 'force', 'power', 'army', 'dignity'.

The concept of 'homeland' is associated mainly with 'the country where I live' (34,0\%), 'love of the Motherland' $(26,8 \%)$, 'willingness to protect it" $(24,4 \%)$, 'involvement into the past and the present' $(15,0 \%)$.

Most students believe that patriotism manifests itself in feelings of love and pride for their country [6]. A third of students believe that patriotism is manifested in the desire to 
live and work in their state, as well as in the willingness to protect the interests of their country (if necessary to take part in warfare). About $15 \%$ of the respondents note that patriotism means a confidence in their future on the territory of the state in which they live.

Main feelings that students have towards their country are positive ones, a sense of pride and respect.

Every third student experiences hope and love for his country. About $18 \%$ of the respondents say they trust their state. Among the negative emotions, the most common feeling is that of disappointment over their country, this option is ticked by $20 \%$ of the students; about $13 \%$ of the respondents say that they have a feeling of mistrust.

Respondents note that they are proud of their country because of the rich history of the Motherland $(50 \%$ of respondents) and the victory in the Great Patriotic War $(53 \%$ of respondents). About $37 \%$ of the students say that they feel proud of the natural resources of the country. Every third student notes that he is proud of the cultural heritage of the country and its position in world politics. Some students mention some additional reasons that they are proud of achievements of Russian athletes and sports in general. One student notes that he is proud of the spirit of a Russian man that cannot be broken. About $5 \%$ of the participants do not experience such feelings.

Thus, young people mostly associate themselves with the citizens of their country and consider Russia their homeland. Ideology is one of the essential factors of forming the civil position, political culture of an individual [4], and symbols are its integral part. The knowledge of the state symbols shows the level of political culture of the youth, their attitude to the state as a whole. The political socialization of the modern young generation took place in the conditions of an unstable society, the absence of an integrative state political ideology [5].

In the course of our study, we identified the reasons for respondents' admission to the main university of the Jewish Autonomous region, a subject of the Far Eastern Federal District.

The main reason for going to Solom-Aleichem Priamursky State University is getting a profession (45\% of the respondents).

Getting a diploma by young people is largely determined by the acquired status in the society. Most female students associate higher education with material opportunities that a future profession can provide. Students' hobbies and interests as well as the amount of wages are the main motive of choosing a profession. It can be explained if we take into account the current situation and standards of living in the country. So, $25 \%$ of university students note that they like their future profession; they believe that when studying they reveal all their talents, and it clearly indicates that professional values are formed at the level of professional interest. Their ideal is a seasoned professional. Many of them think of the career of a politician and businessman. Only two percent want to work in the scientific sphere.
The option 'I think I don't like it' was chosen, to a greater extent, by those respondents, for whom social status and material benefits are important. At the same time, this category of students does not put much effort into studying. Many respondents cannot form their ideal, but some of them dream of living abroad.

Most of the students participating in the survey want to get a job in the field of material production. Most of the future graduates of Solom-Aleichem Priamursky State University are going to work for state institutions, namely the City Administration of Birobidzhan, the Government of the Jewish Autonomous region; eight percent see themselves as experts in the field of advertising and public relations. This area is promising and developing in the JAR, so young people have a real opportunity for employment.

The answer 'in law enforcement agencies (the Ministry of Internal Affairs of the Russian Federation, the Public Prosecutor's Office, etc.)' is the third in the list. This answer is chosen by those students who tick 'justice', 'human rights', 'law', 'freedom' and 'success' as the first and second priorities in the distribution of values. Some young people associate the profession of a police officer with public recognition, material wealth, career development and obtaining a high job position.

Evaluating the current state of the labour market, most of the respondents believe that after graduation, they will be unemployed for some time; it is an initially negative passiveoriented attitude of young people.

Almost thirty per cent of the respondents indicate that they have several employment variants, but so far without clear guarantees (approximately 15 per cent of the young people who chose this answer live in a common-law marriage; have a job and study). The option 'I already know where I will work' was chosen by five percent of students of SolomAleichem Priamursky State University. Twenty-five per cent of Birobidzhan students indicate that they have not thought about the prospects for further employment yet. It is difficult to say if this fact is worth considering, as four percent of the 21 percent previously replied that they would like to live abroad, that the departure was connected with getting a good and well-paid job.

Over the past few decades, students, to a greater extent, prefer a common-law marriage to a registered one. At the same time, family relations are not the last in the rank. We believe that a common-law marriage is economically profitable for students, renting an apartment and running a household are much easier and cheaper for two people, and sexual relations are also stabilized. According to the data obtained, the majority of students participating in the survey have a positive attitude to a common-law marriage, and they consider this form of relations acceptable to themselves. Nowadays, 45 percent of JAR students live in a common-law marriage.

The main obstacle to creating a family is the fact that students do not have their own apartment. Although many people have an opportunity to get a mortgage, high interests and the fear of paying it over a long period of time stop them. 
The reasons for this behaviour may also include the following factors as the lack of the sense of stability and confidence in the future, the desire to keep some freedom and independence.

Fifty-five percent of students studying at SolomAleichem Priamursky State University point out that they are free, that is, at the time of the survey, they have no official relations.

$40 \%$ of young people, who study at Solom-Aleichem Priamursky State University, live well and deny themselves nothing.

Basically, the scholarship and parent's assistance form student's budget. Salary is also important. The reasons for combining work with studies are different. Thus, we can distinguish the following groups of students:

1. Problematic, that is, students from families with low living standards; having their own families. The priorities of this group are to provide for themselves and their families.

2. Independent, that is, the goal of working students of this group is to earn money and spend only for their needs.

3. Assistants, that is, their goal is to help parents. The immediate economic needs of these students replace all other incentives, and in particular, aspirations, one way or another, related to professionalism.

In general, the attitude of young people towards entrepreneurship can also be seen as a positive indicator.

Only $15 \%$ of students dream of having their own business and will strive for it. The same respondents associate their life ideals and aspirations with the career of a businessman. They are attracted by the prospect of being the owner of their business, to have a family, children, as well as to have a prestigious property. In general, these data correspond to Russian trends, according to which only $8 \%$ of the population is able to do entrepreneurial activity. The state pays careful attention to the development of innovative business incubators and small business societies in universities. We believe that in terms of forming, developing and implementing the entrepreneurial potential of the Far Eastern region, first of all, the emphasis should be placed on this group of young people. Regional youth policy in regard to potential entrepreneurs should be aimed at supporting the start of their own business, providing benefits and loans, as well as business-consulting, opportunities of business internship in private companies, various training programs, etc. during their studies.

The main criteria of life success for all respondents are, first of all, a family and true friends. There is a steady trend of consumer strategies.

According to the research, the issues of social and economic stability are important for young people today, as confidence in the future allows young people to plan their future, namely profession, marriage, family, children, property acquisition. Family, children and true friends also occupy a significant place in the hierarchy of values of young people.

During their studies at the university the desire of students to acquire prestige, recognition, to maintain their own prestige increases. Third and fourth year students have already satisfied this need and it is explained by the process of changing their social status in comparison with freshmen (moreover, many senior students start working, have their own family). That is why, in our opinion, this need is the last in the rank among the 3rd year students and 4th year students.

Such values as "self-development' and "achievement" dominate in the hierarchy of life values.

The value of 'self-development'. Respondents long to obtain objective information about the features of their character, abilities, and other characteristics of their personality. They strive for self-improvement, thinking that the potential of a person is almost limitless and that first of all it is necessary to fulfill it ultimately in life, they take things seriously, they are competent in business, lenient to people and their shortcomings, demanding of themselves.

The value of 'achievement'. Respondents strive to achieve concrete and tangible results in different periods of life. They tend to plan their lives carefully, setting specific goals at each stage and believing that the main thing is to achieve these goals. A large number of life achievements often serve as a basis for their high self-esteem.

\section{CONCLUSION}

According to forecasts, in the middle of the XXI century people under 30 can amount to about half of the total population of the planet. What ideals and values will they inherit? What political views will they follow? What parents will they become? What professions will attract them? What religious views will they profess?

Now it is very difficult to predict the answers to these questions. It is important to believe and hope that the continuity of generations and the dialogue of cultures will not be broken, that consumer psychology will not become the meaning of life, that the fate and fortunes of the country will not become alien for young people [8].

The study of value orientations of young people makes it possible to identify the degree of their adaptation to new social conditions and their innovative potential. The future state of the society largely depends on what value basis will be formed.

The study proves that the social portrait of the younger generation is very controversial as at all times. On the one hand, they are romantics, for whom family happiness, true friendship, mutual love are very important. On the other hand, they are rigid pragmatists who value prestige and material well-being. They are ready to make a serious effort to get a good education, but at the same time they want to have an easy and profitable job after graduation. Freedom of thoughts, judgments, and actions are very important for them.

Young people do not have a common axiological field; there are no spheres of life that are unambiguously significant or insignificant for the majority.

Youth problems are not only the problems of the youth, but also the problems of the whole society, if it is interested in its present and future [10]. For young people are the main values of the society. Countries reach a new level of 
civilization development and social progress by means of the successful solution of the social problems of next generations.

As it was mentioned above, the forming of value orientations takes place in the family and in society in the process of education and upbringing; natural, socio-economic and material conditions of human life have an impact. Media, mostly advertisements, can also influence this process. Sometimes advertisements tell us what is good and what is bad. And, as we have already said, such factors as microeconomic, macroeconomic, political, ethical, rational can have influence.

World experience shows that insufficient attention to the younger generation turns it into a powerful factor of destabilization of society [9].

"This choice must be free; otherwise it is not a choice. But even if the choice is free, we must remember that freedom itself is not absolute. Young people should choose, but the choice should not be accidental, moreover wrong. The goals that the society considers to be valuable are appropriate. The system of new values is a stumbling block to Russian reforms. The individual, the people, the society turn into reality, into their culture only those things which they appreciate and believe. If people do not believe in a reform, do not appreciate it, the reform will not be implemented.

In the course of our work we have achieved the objectives set at the beginning of the study. We studied the literature on the subject of our research, considered the theoretical aspects of the problem.

We have selected methods for the study of student's value orientations.

We conducted a comparative analysis of the results of the study and formulated conclusions.

We carried out a theoretical analysis of the literature on the problem of our research, and due to this analysis we offered a definition of value orientations. Value is an importance of something for a person in the world, and only the recognized value is able to perform the most important value function, the function of a behaviour orientation. The value orientation manifests itself in a certain orientation of consciousness and behaviour revealed in socially significant deals and actions [3].

We also studied the place and role of the system of value orientation in the structure of a personality and its development, and gave a psychological characteristic of students.

As a result of the survey, it was revealed that the value of 'family' was the first in the hierarchy of values, the value of 'self-improvement' was the second, and the value of 'health' was the third.

The main reason that encouraged a greater number of the respondents to go to the university was the ability to increase their intellectual level.

\section{REFERENCES}

[1] Allport G.W., Vernon P.E., Lindzey G. A study of values. Text. Boston: Houghton, 1960.

[2] Ananyev BG To the psychophysiology of the student age. Text. // Modern psychological and pedagogical problems of the higher school. L., 1974. Issue. 2. p.3-15.

[3] Bazhenova, N.G., Lutsenko, E.L. Life strategies of Chinese students studying at universities in the border areas of the East of Russia // Global Media Journal, 2016

[4] Giddens A., Politics, Sociology and Social Theory: Encounters with Classical and Contemporary Social Thought, Polity Press, London, Cambridge, 2009, 312.

[5] Kuznetsov N.S. Man: needs and values. Sverdlovsk, 1992.

[6] Lisowski V.T., Youth, love, marriage, family (Case Study), 3rd edn., Science, St. Petersburg, 2008, 368.

[7] Lutsenko, E., Tyurina, Y. Political and legal consciousness of young people in the region (A case study of jewish autonomous region) // International Journal of Environmental and Science Education,2016

[8] Ritzer G., The Wiley-Blackwell Companion to Sociology, WileyBlackwell, 2012, 690.

[9] Sizong By, Lingfei By, The impact of higher education on entrepreneurial intentions of university students in China, Available from Journal of Small Business and Enterprise Development, 15 ( 2008 ), 752-774.

[10] Yadov V.A. Interdisciplinary approach to the study of the relationship between value orientations and observed behavior. Text. M., 1970. 